\title{
ESTUDO DA ENXERTIA HIPOCOTILEDONAR DO MARACUJAZEIRO-AMARELO SOBRE DOIS PORTA-ENXERTOS, ATRAVÉS DE MICROSCOPIA ELETRÔNICA DE VARREDURA ${ }^{1}$
}

\author{
GERALDO COSTA NOGUEIRA FILHO ${ }^{2}$, GIVANILDO RONCATTO ${ }^{3}$, CARLOS RUGGIERO $^{4}$, \\ JOÃO CARLOS DE OLIVEIRA ${ }^{4}$, EUCLIDES BRAGA MALHEIROS ${ }^{4}$
}

\begin{abstract}
RESUMO - O objetivo deste trabalho foi verificar quanto tempo após a realização da enxertia hipocotiledonar ocorre a soldadura ou adesão entre enxerto e porta-enxerto, e também a formação da ponte de calo, verificada pelo total preenchimento da fenda por tecido meristemático secundário (calo). Foram produzidas 56 mudas de maracujazeiro-amarelo (Passiflora edulis Sims f. flavicarpa Deg.) pela enxertia hipocotiledonar em fenda cheia no topo sobre dois porta-enxertos (P. edulis Sims f. flavicarpa Deg. e P. alata Dryander). Aos 0; 3; 6; 9; 12; 15 e 18 dias após a enxertia, coletou-se a região da enxertia de quatro mudas de cada combinação. O material coletado foi fixado em solução de glutaraldeído a 3\%, pós-fixado em tetróxido de ósmio a $2 \%$, desidratado em uma série de álcool etílico $(30 ; 40 ; 50 ; 60 ; 70 ; 80 ; 90$ e 100\%), levado ao secador de ponto crítico $\left(\mathrm{CO}_{2}\right)$, montado, metalizado com ouro - paládio $(35 \mathrm{~nm})$ e, por fim, observados e eletromicrografados em microscópio eletrônico de varredura JEOL JSM 5410 (operado em $15 \mathrm{kV}$ ). Verificou-se que, aos seis dias após a enxertia, a soldadura para o porta-enxerto Passiflora alata já havia ocorrido, o que só foi constatado para Passiflora edulis f. flavicarpa aos nove dias. Também, aos nove dias, observou-se para ambos os portaenxertos a completa formação da ponte de calo, indicando que, a partir daí, pode-se iniciar o processo de aclimatação da muda, para levá-la a um ambiente de menor umidade.
\end{abstract}

Termos para Indexação: Passiflora spp, maracujazeiro-doce, propagação vegetativa, compatibilidade, eletromicrografia.

\section{STUDY OF HYPOCOTYLEDONARY GRAFTING OF PASSION FRUIT PLANT ON TWO ROOTSTOCKS, THROUGH SCANNING ELECTRONIC MICROSCOPY}

\begin{abstract}
The objective of this work was to verify how much time after the accomplishment of the hypocotyledonary grafting occur the weld or the adhesion between graft and rootstock, and also the formation of the callus bridge, verified for the total fulfilling of the slot for secondary meristematic tissue (callus). It was produced 56 seedlings of yellow passion fruit (P. edulis Sims f. flavicarpa Deg.) by the hypocotyledonary grafting in full crack in the top on two rootstocks (P. edulis Sims f. flavicarpa Deg. e P. alata Dryander). On the $0,3,6,9,12,15$ and 18 days after grafting, it was collected the region of the grafting of four seedlings of each combination. The collected material was fixed in a solution of glutaraldehyde at $3 \%$, post-fixed in osmium tetroxide at $2 \%$, dehydrated in a series of ethyl alcohol $(30,40,50,60,70,80,90,100 \%)$, led to the drier of critical point $\left(\mathrm{CO}_{2}\right)$, set up, metalized with gold - palladium $(35 \mathrm{~nm})$ and, finally, observed and eletromicrographed in a scanning electronic microscope JEOL JSM 5410 (operated at $15 \mathrm{kV}$ ). It was discovered that, six days after grafting, the welding for the rootstock $P$. alata had already occurred, which was only evidenced by $P$. edulis f. flavicarpa on the ninth days. Also, on the ninth day, it was observed on both rootstocks, a complete callus bridge formation, indicating that, from this point, you can start the acclimation process of the seedling, to take it to an environment of lower humidity.
\end{abstract}

Index terms: Passiflora spp., sweet passion fruit plant, vegetative propagation, compatibility, electromicrographic.

\footnotetext{
1'(Trabalho 149-09). Recebido em: 15-06-2009. Aceito para publicação em: 25-09-2009.

In memorian

${ }^{3}$ Pesquisador A - Embrapa Acre. Rodovia BR 364 km 14, Zona Rural, Cep 69901180 Rio Branco-AC. E-mail: givanildo@cpafac.embrapa.br ${ }^{4}$ Professor Titular da Unesp/Fcav. Via de acesso Paulo Donato Castellane, s/n Cep 14884-900 Jaboticabal-SP. E-mail: ruggiero@fcav.unesp.br; jocaoliv@fcav.unesp.br; euclides@fcav.unesp.br
} 
O Brasil é o maior produtor mundial de maracujá (Passiflora spp.). Em 2006, apresentou uma produção de 664 mil toneladas, com área de aproximadamente 47 mil hectares, destacando-se o Estado da Bahia como o principal produtor. Em seguida, estão os Estados de São Paulo, Sergipe, Espírito Santo, Pará, Ceará e Minas Gerais como grandes produtores de maracujá (SIDRA/IBGE, 2009).

O termo maracujazeiro envolve várias espécies do gênero Passiflora, da família Passifloraceae (BRUCKNER, 1994). O gênero Passiflora domina amplamente esta família, apresentando cerca de 400 espécies, das quais mais de 150 são endêmicas do Brasil. Este gênero é originário das florestas tropicais da América do Sul, com seu maior centro de dispersão localizado no Brasil-Centro-Norte (PIZA JÚNIOR, 1998).

O maracujazeiro-amarelo (P. edulis Sims f. flavicarpa Deg.), a espécie mais cultivada, é uma planta arbustiva, trepadeira de crescimento contínuo e vigoroso, podendo atingir até 10 metros de extensão. Após 160 dias de idade, os ramos passam a ter um crescimento linear, e as raízes desenvolvemse rapidamente entre 210 e 300 dias. Seu sistema radicular é pouco distribuído, concentrando-se num raio de $50 \mathrm{~cm}$ do tronco e na profundidade de 30-40 $\mathrm{cm}$. A absorção de nutrientes pelas plantas intensificase a partir de 250 dias de idade, que corresponde ao estádio de pré-frutificação. O crescimento dos frutos é rápido, completando-se entre 55 e 95 dias, quando se inicia a maturação (RUGGIERO et al., 1996).

O maracujá-amarelo é uma planta de clima tropical, com ampla distribuição geográfica, encontrando no Brasil excelentes condições ecológicas para o seu cultivo. Embora seja uma exploração comercial recente, a cultura do maracujá está em franca expansão, tanto na produção de fruta para o consumo in natura como na produção de suco concentrado. Entretanto, com o aumento da área plantada, aparecem problemas culturais, como a baixa longevidade e produtividade, manejo fitossanitário inadequado, nutrição e adubação desequilibrada, utilização e comercialização, ocasionados pela escassez de informações técnicas adequadas (LIMA, 1999).

Com isso, a enxertia apresenta-se como uma técnica apropriada para solucionar problemas fitossanitários do solo para o maracujazeiro. Ela já foi utilizada comercialmente em outros países, como na África do Sul. Suas conhecidas vantagens são a reprodução fiel das plantas-matrizes, o controle de pragas e doenças através do uso adequado do portaenxerto, resistência à seca, redução do volume de copa e influência na qualidade do fruto e/ou suco (NOGUEIRA FILHO; RUGGIERO, 1998).

A enxertia em maracujazeiro é uma prática relativamente recente, ainda não incorporada como usual na cultura, devido a oscilações quanto ao pegamento e observações quanto ao desenvolvimento das plantas no campo. A enxertia hipocotiledonar pode ser uma alternativa interessante ao processo.

A base da enxertia é a união dos biontes (hipobionte e epibionte), a qual ocorre pelo contato e entrelaçamento dos calos, produzidos pelo tecido cambial do porta-enxerto e do enxerto, como resultado da reação ao corte dos tecidos (JANICK, 1966).

Vários estudos têm sido realizados a respeito da formação da união da enxertia com plantas herbáceas e lenhosas. Assim como um meristema secundário é necessário para a formação de raízes e gemas adventícias, também é necessária a formação de um novo meristema secundário (calo), entre os tecidos do enxerto e do porta-enxerto, para que a união da enxertia ocorra com sucesso. As peças da enxertia que foram originalmente preparadas e colocadas em contato estreito, não se movem ou crescem juntas. Assim, a união é formada inteiramente por células que se desenvolvem após a execução da enxertia. A união da enxertia é inicialmente formada por células do calo dividindo-se rapidamente, originadas do enxerto e porta-enxerto, as quais depois se diferenciam para formar o câmbio vascular (um meristema lateral) e o sistema vascular associado (HARTMANN et al.,1997).

O desenvolvimento de uma enxertia compatível é tipicamente compreendido por três principais eventos: adesão ou soldadura entre enxerto e porta-enxerto; proliferação das células do calo na região da enxertia ou ponte de calo ('callus brigde'); e a diferenciação celular através da região da enxertia (HARTMANN et al.,1997).

Durante a calogênese, as células passam a dividir-se até que todo o espaço vazio entre os biontes seja completamente preenchido. Porém, apesar da regeneração das duas partes, não ocorre fusão dos tecidos, eles apenas se misturam (JESUS, 1994).

O objetivo deste trabalho foi verificar quanto tempo após a realização da enxertia hipocotiledonar ocorre a soldadura ou adesão entre enxerto e portaenxerto, e também a formação da ponte de calo, verificada pelo total preenchimento da fenda por tecido meristemático secundário.

A primeira fase foi realizada no Ripado de Fruticultura do Departamento de Produção Vegetal, e a segunda, no Laboratório de Microscopia Eletrônica,ambos pertencentes à Faculdade de 
Ciências Agrárias e Veterinárias - Câmpus de Jaboticabal, da Universidade Estadual Paulista (FCAV/UNESP-Jaboticabal-SP).

$\mathrm{Na}$ primeira fase, ocorrida em janeiro de 2002, realizaram-se 56 enxertias por garfagem em fenda cheia no topo, do tipo hipocotiledonar. Quando os porta-enxertos e enxertos atingiram a fase de enxertia, cerca de 6 a $8 \mathrm{~cm}$ de altura e uma a duas folhas definitivas, o que ocorreu com cerca de 30 dias após a semeadura para as espécies mais precoces ou vigorosas, e 90 para as de crescimento mais lento, realizou-se a enxertia. Umedeceu-se previamente o substrato do porta-enxerto de forma a retirá-lo com um mínimo de danos ao seu sistema radicular. Então, decepou-se o mesmo abaixo dos cotilédones e abriuse uma fenda longitudinal $(1,0 \mathrm{~cm})$. Procedeu-se a retirada do garfo, decepando-se a plântula doadora abaixo dos cotilédones e fez-se uma cunha em bisel duplo de forma a expor os tecidos do câmbio, utilizando-se para isso de uma lâmina de platina bem afiada do tipo "gilete". Então, juntaram-se enxerto e porta-enxerto com cuidado para fazer-se coincidirem os tecidos cambiais e utilizou-se de fita adesiva (crepe) para envolver a região da enxertia, protegendo-a, evitando o seu ressecamento, assim como o excesso de umidade e funcionando também como tutor da muda.

Imediatamente após a realização da enxertia propriamente dita, a muda já enxertada foi transplantada em copo plástico $(200 \mathrm{~mL})$ com o mesmo substrato utilizado anteriormente. Já transplantada, a muda foi tutorada por uma estaquinha de madeira $(18 \mathrm{~cm})$ e coberta com um saco plástico transparente $(15 \times 20 \mathrm{~cm})$, que foi preso com um elástico de borracha para formar uma câmara úmida. Posteriormente, as mudas foram colocadas em bandeja plástica com uma lâmina de cerca de $1,0 \mathrm{~cm}$ de água e deixadas à sombra, no ripado. Aos dez dias, retirou-se o elástico de borracha e, aos quinze, removeu-se o saco plástico; aos vinte dias, foram levadas para uma zona limítrofe entre a sombra e a meia-sombra; aos vinte e cinco dias, foram retiradas das bandejas, e, aos trinta dias, foram levadas para o ambiente de meia-sombra do ripado.

Enquanto ainda nas bandejas, a água era reposta sempre que necessário. Após deixarem as bandejas, as mudas foram regadas diariamente com o sistema de microaspersores colocado junto à cobertura do ripado. A cada quinze dias, as mudas eram regadas com uma solução de 10 gotas por litro de água do produto comercial Ouro-verde $\left(\mathrm{N} 6 \%, \mathrm{P}_{2} \mathrm{O}_{5}\right.$ $6 \%, \mathrm{~K}_{2} \mathrm{O} 8 \%$, Mg 0,5\%, S 0,5\%, B 0,03\%, Zn 0,05\%, $\mathrm{Fe} 0,1 \%$, Mn 0,03\%), fertilizante líquido.

A variedade-copa utilizada foi o maracujazeiro- amarelo (Passiflora edulis f. flavicarpa Degener). Este foi enxertado sobre dois porta-enxertos diferentes: o próprio P. edulis f. flavicarpa e o maracujazeiro-doce (P. alata Dryander), sendo 28 para cada combinação enxerto/porta-enxerto. A região da enxertia, mais cerca de $0,5 \mathrm{~cm}$ do enxerto e porta-enxerto de 04 plantas, para cada porta-enxerto, foram coletados nos tempos de $00 ; 03 ; 06 ; 09 ; 12$; 15 e 18 dias após a enxertia. O material coletado foi colocado para fixação e armazenagem em solução resfriada de gluteraldeído a $3 \%$, em tampão de fosfato de potássio a $0,05 \mathrm{M}$ e pH 7,4. Logo após, foi devidamente identificado e novamente acondicionado em refrigerador comum à temperatura de cerca de $10^{\circ} \mathrm{C}$.

$\mathrm{Na}$ segunda fase, ocorrida em agosto de 2002, seguindo o protocolo descrito por Santos e Maia (1997), as amostras foram lavadas seis vezes consecutivas em água destilada, e levadas à capela com sistema de exaustão para pós-fixação em tetróxido de ósmio a $2 \%$, no mesmo tampão de fosfato de potássio a $0,05 \mathrm{M} \mathrm{e} \mathrm{pH} \mathrm{7,4,} \mathrm{por} \mathrm{cerca} \mathrm{de}$ 12 horas. Posteriormente, foram novamente lavadas por seis vezes com água destilada. A seguir, foram desidratadas em uma série gradual de álcool etílico $30,40,50,60,70,80,90$ e $100 \%$, nesta última, por três vezes, e permanecendo imersas em cada uma por 20 minutos. Depois, foram secas em secador de ponto crítico, utilizando-se de $\mathrm{CO}_{2}$, montadas, metalizadas com cerca de $35 \mathrm{~nm}$ de ouro-paládio. Em seguida, foram observadas e eletromicrografadas em microscópio eletrônico de varredura JEOL JSM 5410 , operado em $15 \mathrm{kV}$.

Analisando as regiões da enxertia coletadas, verificou-se que, aos três dias após a enxertia, em nenhum dos dois porta-enxertos havia ocorrido a soldadura entre as peças. Já aos seis dias após a enxertia, havia ocorrido a soldadura para o portaenxerto $P$. alata, embora a fenda não estivesse totalmente preenchida com tecido parenquimático. E não havia ainda ocorrido a soldadura para o porta -enxerto P. edulis f. flavicarpa a essa época. E aos nove dias, para ambos os porta-enxertos, havia ocorrido a soldadura (Figuras 01 e 02).

Os resultados observados corroboram a decisão de, aos dez dias, iniciar a aclimatação da muda pela retirada da liga de borracha que prendia o saco plástico da câmara úmida, permitindo maior troca gasosa com o exterior. E posteriormente, aos quinze dias, ocorreu a remoção do saco plástico, desfazendo-se totalmente a câmara úmida.

Também se pode observar que todo o espaço entre as peças (enxerto e porta-enxerto) foi preenchido por tecido parenquimático cicatricial 
abundante (ponte de calo) aos nove dias após a enxertia. Já Rezende (2000), observou, através de microscopia eletrônica de varredura, que em enxertos de mesa de uva 'Rubi' em estacas herbáceas do porta-enxerto IAC 313, aos 60 dias após a enxertia, houve a formação de calo deficiente entre os tecidos do enxerto e do porta-enxerto. $E$ mesmo aos oito meses de idade, o tecido cicatricial (calo) formado não foi suficiente para promover a cicatrização. Entretanto, nas mudas de enxertia de mesa em estacas lenhosas, foi constatada uma perfeita soldadura dos tecidos, onde uma massa compacta (novo tecido cambial) cobria toda a fenda aberta durante a realização da enxertia. Isso assemelha-se ao que foi observado por Oliveira et al. (2008) em abacateiro variedade 'Fortuna', que obtiveram pegamento na enxertia aos doze meses de idade, com a cicatrização e substituição de tecido necrosado por tecido novo, proporcionando uma eficiente soldadura.

Dessa forma, vê-se que a enxertia verde (com material herbáceo) presta-se melhor e de forma mais rápida à formação de mudas do maracujazeiro, diferentemente do que foi constatado na videira pelo autor mencionado anteriormente.
Sendo assim, foi verificado nesse experimento que, aos seis dias após a enxertia, a soldadura para o porta-enxerto $P$. alata já havia ocorrido, o que só foi constatado para $P$. edulis f. flavicarpa aos nove dias. Neste mesmo tempo, verificou-se, para ambos os porta-enxertos, a completa formação da ponte de calo, indicando que, a partir daí, pode iniciar-se o processo de aclimatação da muda, para levá-la a um ambiente de menor umidade. Isso está de acordo com o que foi observado por Nogueira Filho (2003), Nogueira Filho et al. (2005), Silva et al. (2005) e Lima et al. (2006), que obtiveram êxito na execução da enxertia e no pegamento em espaço de tempo relativamente curto, podendo ser um indicativo de que as mudas serão levadas a campo precocemente.

Assim, pode-se concluir que a enxertia hipocotiledonar do maracujazeiro-amarelo sobre o porta-enxerto $P$. alata inicia sua cicatrização precocemente, aos seis dias após a enxertia. A soldadura no ponto de enxertia completou-se aos 10 dias após sua execução, para os porta-enxertos $P$. alata e P. edulis f. flavicarpa, constituindo-se como indicativo de retirada da câmara úmida.
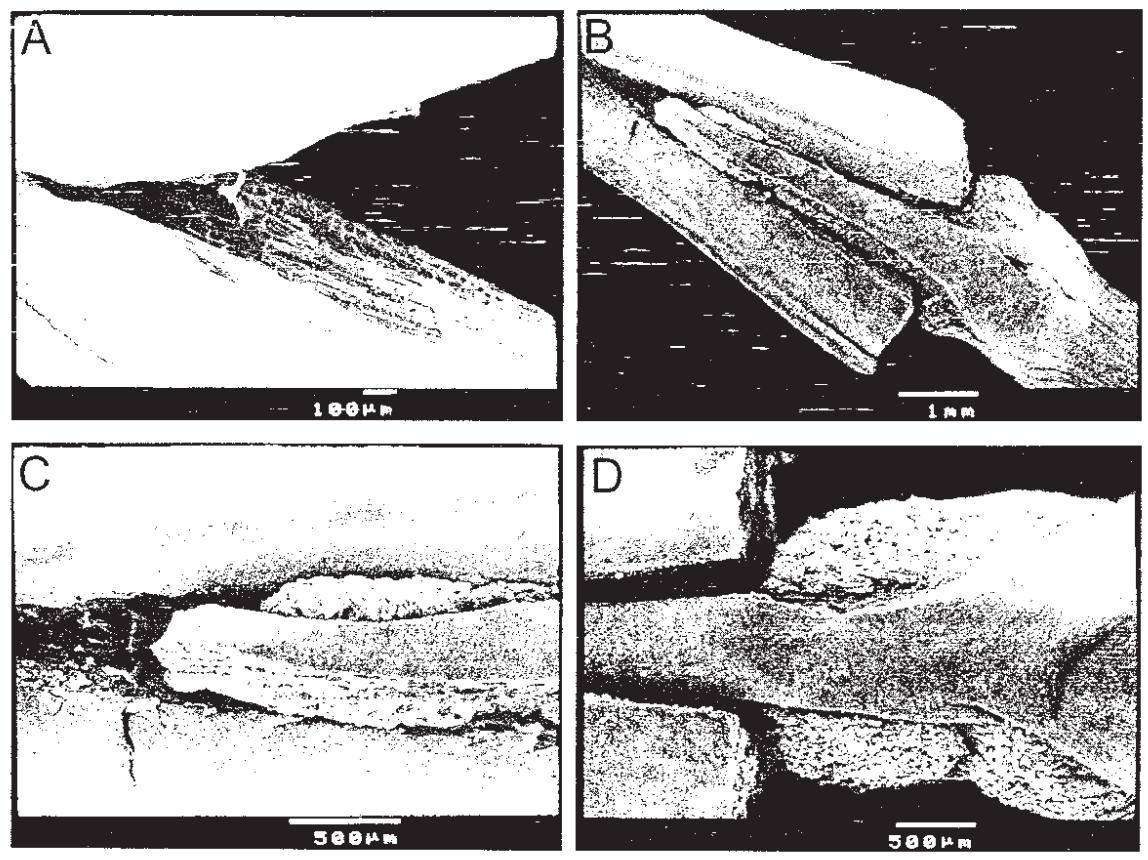

FIGURA 01 - Eletromicrografias de varredura da região da enxertia em mudas de maracüjazeiro-amarelo pela enxertia hipocotiledonar, sobre o porta-enxerto Passiflora alata. A) Corte da fenda no momento da enxertia (tempo 0 dia). B) Região da enxertia, com as peças já soldadas, seis dias após (tempo 6 dias). C e D) Região da fenda e da cunha, mostrando tecido parenquimático cicatricial, seis dias após a realização da enxertia (tempo 6 dias). 

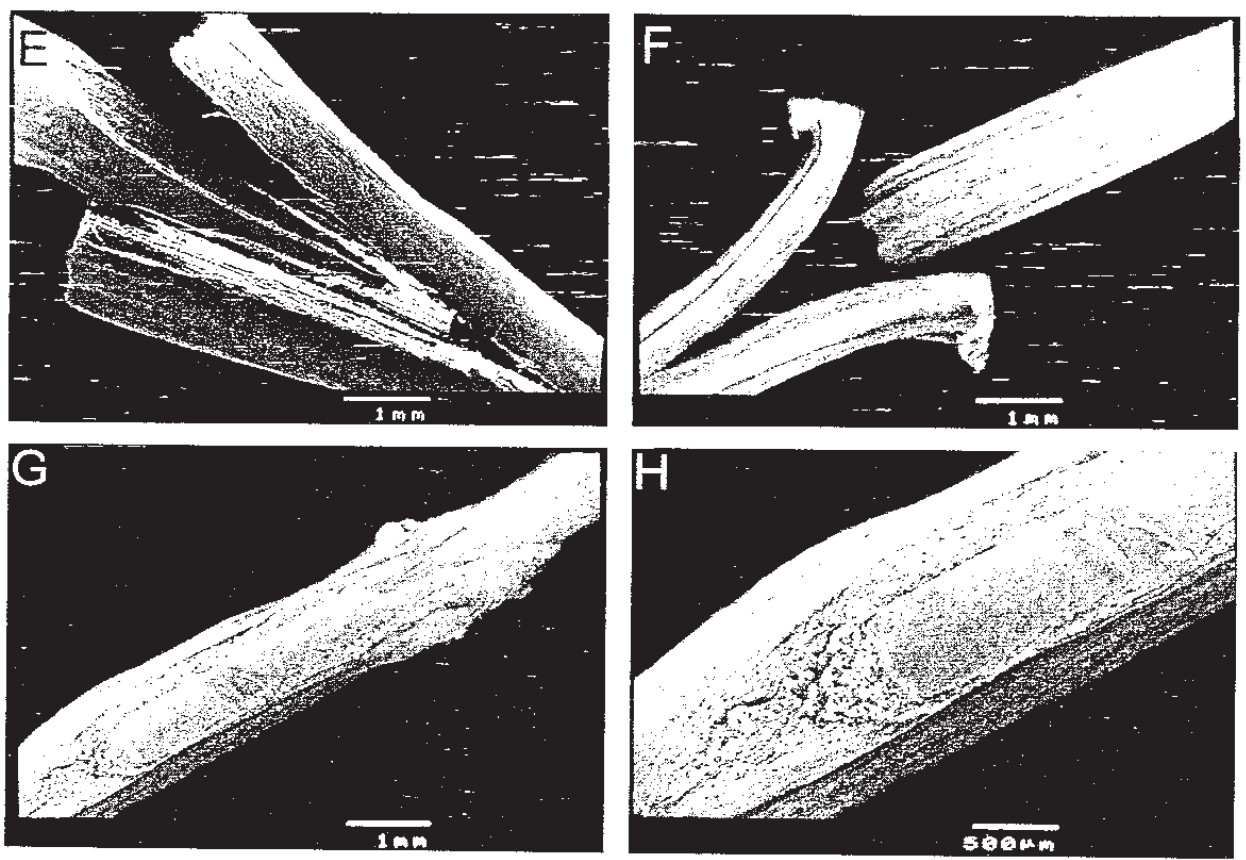

FIGURA 02 - Eletromicrografias de varredura da região da enxertia em mudas de maracujazeiro-amarelo pela enxertia hipocotiledonar, sobre o porta-enxerto Passiflora edulis f. flavicarpa. E) Peças ainda não soldadas, três dias após (tempo 3 dias). F) Peças ainda nâo soldadas, seis dias após (tempo 6 dias). G e H) Região da enxertia com as peças já soldadas, mostrando tecido parenquimático cicatricial, nove dias após (tempo 9 dias).

\section{REFERÊNCIAS}

BRUCKNER, C.H. Autoincompatibilidade em maracujazeiro. In: SÃO JOSÉ, A R. Maracujá: produção e mercado. Vitória da Conquista: DFZ/ UESB, 1994. p. 6-18.

HARTMANN, H.T.; KESTER, D.E.; DAVIES JUNIOR, F.T., GENEVE. R.L. Plant propagation: principies and practices. New Jersey: Prentice Hall, 1997. p. 770.

JANICK, J. A ciência da horticultura. Rio de Janeiro: Freitas Bastos, 1966. p. 485.

JESUS, A.M.S. Obtenção antecipada de mudas de videira (Vitis spp). Lavras, 1994. 75f. Dissertação (Mestrado em Fitotecnia) - Escola Superior de Agricultura de Lavras, Lavras, 1994.

LIMA, A. de A. (Coord.). O cultivo do maracujá. Cruz das Almas, BA: Embrapa Mandioca e Fruticultura, 1999. 130 p. (Circular Técnica, 35).

LIMA, A. de A.; CALDAS, R.C.; SANTOS, V. da S. Germinação e crescimento de espécies de maracujá. Revista Brasileira de Fruticultura, Jaboticabal, v.28, 2006.

NOGUEIRAFILHO, G.C. Enxertia hipocotiledonar de maracujazeiro-amarelo em diferentes espécies de passifloras silvestres. 2003. 119 f. Tese (Doutorado em Agronomia) - Faculdade de Ciências Agrárias e Veterinárias, Universidade Estadual Paulista, Jaboticabal, 2003.

NOGUEIRA FILHO, G. C.; RUGGIERO, C. Implicações da autoincompatibilidade na produção de mudas e no melhoramento do maracujazeiro \{Passiflora edulis Sims. f. flavicarpa Deg.). Boa Vista: Embrapa Roraima, 1998. 18 p. (Série Documentos,3).

NOGUEIRA FILHO, G.C.; RONCATTO, G.; RUGGIERO, C.; OLIVEIRA, J.C.; MALHEIROS, E.B. Propagação vegetativa do maracujazeiroconquista de novas adesões. In: FALEIRO, F.G.; JUNQUEIRA, N.T.V.; BRAGA, M.F. (Ed.). Maracujá: germoplasma e melhoramento genético. Planaltina: Embrapa Cerrados, 2005, p.340-58. 
OLIVEIRA, I.V. de M.; CAVALCANTE, I.H.L.; FRANCO, D.; MARTINS, A.B.G. Influência da época do ano no sucesso da enxertia nas variedades de abacateiro Hass e Fortuna. Revista Brasileira de Fruticultura, Jaboticabal, v.30, n.4, p. 1162-1166, 2008.

PIZA JÚNIOR, C. de T. A cultura do maracujá na região Sudeste do Brasil. In: RUGGIERO, C. (Ed). Maracujá: do plantio à colheita. Jaboticabal: FUNEP, 1988. p.20-48.

REZENDE, L.P. Produção de mudas de videira (Vitis spp) por enxertia de mesa em estacas herbáceas dos porta-enxertos IAC 313 'Tropical' e IAC 766 'Campinas', 2000. 104 f. Tese (Doutorado em Produção Vegetal) - Faculdade de Ciências Agrárias e Veterinárias, Universidade Estadual Paulista, Jaboticabal, 2000.

RUGGIERO, C.; SÃO JOSÉ, A.R.; VOLPE, C.A.; OLIVEIRA，J.C.; DURIGAN, J.F.; BAUMGARTNER, J.G.; SILVA, JR. da; NAKAMURA, K.; FERREIRA, M.E.; KAVATI, R.; PEREIRA, V.P. Maracujá para exportação: aspectos técnicos da produção. Brasília: EmbrapaSPI, 1996. 64p.
SANTOS, J. M. dos; MAIA, A.S.A. SEM improved technique for studying host-pathogen interactions of sedentary nematodes and for documentation of perineal patterns of Meloidogyne spp. Microscópica Acta, Stuttgart, v.6, p. 562-563. 1997.

SIDRA/IBGE - Instituto Brasileiro de Geografia e Estatística. Produção Agrícola Municipal: maracujá. Brasília: Ministério do Planejamento, Orçamento e Gestão. Disponível em: < http://www. sidra.ibge.gov.br>. Acesso em: 19 fev. 2009.

SILVA, F.M.; CORREA, L. de S.; BOLIANI, A.C.; SANTOS, P. C. dos. Enxertia de mesa de Passiflora edulis Sims f. flavicarpa Deg. sobre Passiflora alata Curtis, em ambiente de nebulização intermitente. Revista Brasileira de Fruticultura, Jaboticabal, v.27, n.1, p.98, 2005. 